\title{
Valor de las instrucciones previas
}

\author{
Value of previous instructions
}

\section{José María Maya}

Médico, magister en Salud Pública, magister en Dirección Universitaria y magister en Dirección y Gestión de la Seguridad Social; profesor titular, Universidad CES; decano general, Escuela de Ciencias de la Vida. Universidad EIA, Medellín, Colombia

\section{RESUMEN}

Se presenta el caso de un paciente de 80 años de edad con diagnóstico de enfermedad de Alzheimer desde 12 años antes y con antecedentes de otras enfermedades crónicas, a quien, en una consulta, el médico dermatólogo le diagnosticó un melanoma maligno con metástasis, y le inició tratamiento médico y quirúrgico para el control de su neoplasia maligna.

Previamente, y estando en uso de sus facultades mentales, el paciente le había pedido a su familia que, si aparecía una nueva enfermedad, no le dieran tratamiento, excepto los cuidados paliativos que le permitieran una muerte digna.

El médico hizo caso omiso de esta manifestación y sometió al paciente a tratamientos agresivos para su neoplasia maligna, que prolongaron su sufrimiento y no le permitieron una muerte digna.

PAlabRas CLAVE: ética, Alzheimer, distanasia, cuidados paliativos,voluntad anticipada.

\section{SUMMARY}

Presentation of the case of a patient of 80 years with a diagnosis of Alzheimer's disease for 12 years and with a history of other chronic pathologies to whom the dermatologist in a consultation, diagnoses a malignant melanoma with metastasis and starts medical and surgical treatment for control of his malignant pathology. The patient previously and in use of his mental faculties had informed his family that if a new pathology appeared he did not want to receive treatment for it except for palliative care that would allow him a dignified death. The doctor ignored this manifestation and subjected the patient to aggressive treatments for his pathology that prolonged his suffering and did not allow him a dignified death.

KEY WORDS: Ethics, Alzheimer, dysthanasia, palliative care, advance will

\author{
Correspondencia: \\ Jose Maria Maya \\ Email: \\ josemariamayamejia@gmail. \\ com \\ Recibido: 22/12/18 \\ Aceptado: 25/12/18 \\ Conflictos de interés: \\ No se reportan conflictos de \\ interés.
}

Financiación:

Ninguna. 


\section{CASO DE ÉTICA N ${ }^{\circ} 7$}

Jorge es un paciente de 80 años de edad con diagnóstico de enfermedad de Alzheimer desde 12 años antes. Igualmente, tiene antecedentes de hipertensión arterial sistémica, diabetes mellitus de tipo II y cataratas bilaterales. Está casado, tiene dos hijas, vive con su esposa y, por el avance de la enfermedad, requiere ayuda permanentemente para sus actividades básicas.

Desde el principio de la enfermedad, Jorge fue consciente de lo que le ocurría, pues tanto su padre como su hermano padecieron la enfermedad y murieron a causa de ella. Poco a poco fue consciente de estar presentando los mismos síntomas que sus dos familiares y, por ello, un día decidió hablar de ello con su esposa y acudir al neurólogo, quien confirmo sus sospechas: le diagnosticó enfermedad de Alzheimer.

Para ese momento, el paciente ya tenía claramente decidido qué quería para su atención futura. Sabía que su calidad de vida iría disminuyendo progresivamente y había decidido que, por nada del mundo, quería terminar su vida como su padre y hermano: degradado, incapacitado, precisando ayuda permanentemente y habiendo perdido el control sobre sí mismo. Se reunió con su esposa y dos hijas, y les comunicó que su decisión era que, en caso de que le fuera diagnosticada otra enfermedad o una complicación de las actuales, no quería recibir un tratamiento que buscara prolongar la no-vida que le esperaba y solo deseaba cuidados paliativos que le permitieran morir con dignidad. Acudió donde su neurólogo y le comunicó su decisión, pidiéndole que se respetara su voluntad.

A los 80 años es llevado por su esposa al médico dermatólogo por una lesión en la piel, que muestra que está creciendo. El médico dermatólogo hace una biopsia y otros exámenes y, finalmente, le comunica a la esposa, ya que el estado mental del paciente no le permite comprender la información recibida, que el diagnóstico es de un melanoma maligno con metástasis. Recomienda la resección del tumor primario, además de radioterapia para las metástasis. Le explica a la esposa que su supervivencia puede incrementarse con estas medidas. La esposa le comenta al médico la decisión que el paciente había tomado cuando le comunicaron el diagnóstico de enfermedad de Alzheimer, en el sentido de solo recibir cuidados paliativos que le ayudaran a tener una muerte digna, sin sufrimiento, y su rechazo de cualquier medida que alargara una vida que él consideraba sería de mala calidad y, por ende, indigna para un ser humano.

El médico manifiesta su desacuerdo con la posición del paciente y le insiste a la esposa que, dado que no hay un documento de voluntad anticipada, debe hacerse lo que él, como especialista en el tema, recomienda que es mejor para el paciente. La esposa cede ante la manifestación enfática del médico y permite que se lleve a cabo la terapia propuesta.

El paciente sobrevivió 8 meses con un deterioro progresivo de su estado general, sin reconocer a su esposa ni a sus hijas, totalmente dependiente de ellas y en un estado de regresión indigno de un ser humano. A los ocho meses su deterioro era muy acentuado, por lo cual el médico se decidió por su internación en un hospital. Allí sobrevivió 15 días, hasta que presentó un paro cardiorrespiratorio que no recibió reanimación por el equipo de emergencia, por oposición de las hijas que lo acompañaban.

Al salir del hospital, las hijas se quejaron de la calidad de vida de su padre en los últimos meses y del malestar que el no haber respetado su voluntad generó en ellas. 


\section{CUESTIONAMIENTOS ÉTICOS}

1. ¿El no disponer de un documento escrito de voluntades anticipadas, autoriza el ignorar la voluntad que el paciente, en uso de sus facultades legales mentales?, le expresó verbalmente a su familia?

2. ¿Podría considerarse el tratamiento realizado como encarnizamiento terapéutico (distanasia)?

3. ¿Los cuidados paliativos que debería haber recibido este paciente son un derecho humano, al igual que el respeto por su decisión autónoma de no recibir ningún tratamiento?

\section{Ética continúa en la página xxx}

